\title{
cantem \\ Optical Technologies Applied to Cultural Heritage
}

\author{
Antonio A. Fernandez-Balbuena * (D) and Daniel Vazquez-Molini
}

Departamento de Óptica, Universidad Complutense de Madrid, 28016 Madrid, Spain; dvazquez@ucm.es

* Correspondence: antonioa@ucm.es

check for

updates

Citation: Fernandez-Balbuena, A.A.; Vazquez-Molini, D. Optical Technologies Applied to Cultural Heritage. Heritage 2022, 5, 359-361. https://doi.org/10.3390/ heritage 5010020

Received: 26 January 2022 Accepted: 7 February 2022

Published: 9 February 2022

Publisher's Note: MDPI stays neutral with regard to jurisdictional claims in published maps and institutional affiliations.

Copyright: (c) 2022 by the authors. Licensee MDPI, Basel, Switzerland. This article is an open access article distributed under the terms and conditions of the Creative Commons Attribution (CC BY) license (https:// creativecommons.org/licenses/by/ $4.0 /)$.
Who knows about light? Who knows about art? These are difficult questions to answer. Optical technologies, which can be applied to cultural heritage, are very diverse and can be used for many purposes. Nowadays, new developments in optical technologies have made it possible to apply these technologies in areas where we did not know it was possible and to obtain data that seemed unreachable. We have a higher instrument accuracy, a higher acquisition velocity, smaller devices, and relatively lower-cost systems. All these factors have opened doors that were once thought to be beyond scientific limits. Today, we have new horizons and possibilities. On the other hand, from a cultural, economic, and social point of view, cultural heritage plays a key role in advanced societies every day. It is very difficult to summarize all the fields in which optical technologies are helpful and non-destructive tools can be used for restoration and analysis. We think that proposals such as this Special Issue are very important for improving our knowledge of various scientific areas. Let us here quote the motto of our university, the Complutense University of Madrid, Libertas Perfundet Omnia Luce (liberty lights everything), which we can applied to our field as "the light will make free".

When we issued the call for papers for the Special Issue "Optical Technologies Applied to Cultural Heritage", our primary objective was to put together a variety of articles that could explain or at least shed some light on these two questions. To achieve this, we invited several authors to contribute papers from their field in relation to the topics of photonic restoration, spectroscopy analysis, light and damage, hyperspectral image acquisition and processing, light-based technique characterization (optical microscopy, FTIR, Raman, X-ray...), and color and visual implications. Additionally, we received some other papers from scientists all around the world. This Special Issue has reached a total of 14 papers, including reviews, research articles, and others that will help us to explain the complexity of working in the field of cultural heritage.

The 14 contributions give special focus to the following items:

- $\quad$ Non-invasive technologies;

- Cleaning methods;

- Characterization of color, damage, LED lighting;

- Monitoring ageing;

- Analytical investigation;

- Image analysis;

- Virtual restoration;

- Vision and color;

- Technical and case studies.

In this Special Issue, we present papers on a mix of optical technologies related to different restoration needs, as well as a specific paper related to a digital representation of the Tower of the Captive located in the Alhambra palace in Granada [1]. It is clear that humankind needs light to see in the dark-for example, the behavior of Paleolithic groups was determined by how long the light of their torches lasted, since deeper parts of the Paleolithic caves required light not only to access them but also to carry out artistic activities [2]. 
At present, cultural heritage lighting has been studied quite extensively. The International Commission on Illumination (CIE) provides several guides for the use of lighting. For instance, there is an exhaustive guide on the need to prevent damage caused by lighting in museums [3]. However, this guide has some limitations that should be overcome through further research. The damage function illustrates one of these relevant areas that should be studied. This is related to wavelength and five material categories-namely, low-quality paper, cotton paper, oil paint over canvass, textiles, and watercolors on fabric paper; however, the number of relevant materials that need to be studied is considerable. As can be seen, there is still much work to do. Artwork damage has been studied in the literature, sometimes in relation to museum objects [4] and usually in relation to particular materials such as Japanese lacquer [5].

Scientific studies on cultural heritage conservation have been carried out using noninvasive techniques. Optical technologies are therefore a great ally in this area. As an example, we present two detailed papers on the issue of non-invasive measurements: one of them deals with a combination of imaging and spectroscopic techniques with principal component analysis (PCA) and describes the pigment spatial distribution over the largeformat picture of Purísima Concepción located in México [6].

Dr. Dorukalp conducted an interesting study regarding the dilemma concerning light, damage, and visibility when using LED light sources in museums. The author obtained the color quality function related to energy efficiency for a multi-primary LED light source; this is one of the greatest challenges when lighting artworks. Finally, he presents a 3D representation of conflicting parameters (color quality vs. damage) that should be studied carefully to improve lighting conditions and reduce damage. With a tunable RGB light source, optimal spectral combination can reduce damage while maintaining a good level of lighting [7].

Benítez et al. published an interesting article about the digital representation of an historical building. In their case, they explain the workflow followed to reach the digital representation of the whole interior of the Tower of the Captive located in the Alhambra palace in Granada. The objective was to create a photorealistic 3D model to contribute to the dissemination of cultural heritage. Virtual reality (VR) environments are potential systems that can be used to visualize 3D models [1]. The photorealistic 3D projection of this scene could contribute to reducing the damage caused to this fragile building due to high amount of people wanting to visit it. Additionally, this is an example of a new form of experiencing art through virtual reality or augmented reality. For this projection, the authors studied different natural lighting conditions so that the interior of the building could be virtually observed in any desired condition.

Ángela Gómez proposes a review of different virtual restoration techniques and presents projection mapping as a necessary process to obtain a good calibration for future projection lighting for restoration applications. Projected lighting can be useful for restoration and lighting by employing algorithms to reduce damage while improving the appearance of color. There are some artworks, such as Dali's 1926 picture "Dos Figuras", that cannot be traditionally restored due to the canvas and pigment status; therefore, new technologies such as light projection techniques should be applied.

Finally, the Guest Editors would like to reflect on the issue of lighting and cultural heritage. Cultural heritage is a treasure that humankind has received, so we are responsible for maintaining it for future research and contemplation. This may be difficult to achieve, but non-invasive scientific techniques have been proven to be of great importance in permitting curators to make good decisions about the conservation process. Therefore, curators and scientists must work together to make this work possible.

Author Contributions: Writing-original draft preparation, A.A.F.-B. and D.V.-M. All authors have read and agreed to the published version of the manuscript.

Funding: This research has been funded by project number RTI2018-097633-A-100 of the Ministry of Science and Innovation of Spain. 
Conflicts of Interest: The authors declare no conflict of interest.

\section{References}

1. Benítez, A.J.; Prieto Souto, X.; Armenteros, M.; Stepanian, E.M.; Cantos, R.; García-Villaraco, M.; Solano, J.; Gómez Manzanares, Á. Multi-Camera Workflow Applied to a Cultural Heritage Building: Alhambra's Torre de la Cautiva from the Inside. Heritage 2022, 5, 21-41. [CrossRef]

2. Medina-Alcaide, M.Á.; Garate, D.; Intxaurbe, I.; Sanchidrián, J.L.; Rivero, O.; Ferrier, C.; Mesa, M.D.; Pereña, J.; Líbano, I. The conquest of the dark spaces: An experimental approach to lighting systems in Paleolithic caves. PLoS ONE 2021, 16, e0250497. [CrossRef] [PubMed]

3. CIE. Control of Damage to Museum Objects by Optical Radiation; CIE 157-2004: Vienna Austria, 2004.

4. Cuttle, C. Damage to museum objects due to light exposure. Int. J. Light. Res. Technol. 1996, 28, 1-9. [CrossRef]

5. Nakagoshi, K.; Yoshizumi, K. Degradation of Japanese Lacquer under Wavelength Sensitivity of Light Radiation. Mater. Sci. Appl. 2011, 2, 1507-1515. [CrossRef]

6. Pérez, M.; Cano, N.; Ruvalcaba-Sil, J.L.; Mitrani, A.; de Lucio, O.G. Technical Non-Invasive Study of an 18th Century NovoHispanic Panel Painting. Heritage 2021, 4, 3676-3696. [CrossRef]

7. Durmus, D. Characterizing Color Quality, Damage to Artwork, and Light Intensity of Multi-Primary LEDs for Museums. Heritage 2021, 4, 188-197. [CrossRef] 